\title{
Patients' Satisfactions from Public Hospitals Services in Alkharj and Hotat Bani Tamim: A Comparative Study
}

\author{
Mohammad Tariq Intezar ${ }^{1}$, Khalid Abdullah Alotaibi ${ }^{1} \&$ Ahmed Saied Rahama Abdallah ${ }^{1}$ \\ ${ }^{1}$ College of Business Administration, Prince Sattam bin Abdulaziz University, Hotat Bani Tamim, Kingdom of \\ Saudi Arabia (KSA) \\ Correspondence: Mohammad Tariq Intezar, College of Business Administration, Prince Sattam bin Abdulaziz \\ University, P.O Box-1004, Hotat Bani Tamim-1149, Kingdom of Saudi Arabia (KSA). Tel: 966-11-588-7500; \\ 966-50-998-4364. E-mail: t.mohamad@psau.edu.sa; tariqintz@gmail.com
}

\author{
Received: February 10, 2016 Accepted: March 14, 2016 Online Published: April 19, 2016 \\ doi:10.5539/ass.v12n5p167 URL: http://dx.doi.org/10.5539/ass.v12n5p167
}

\begin{abstract}
Patients' satisfaction at public hospitals is an integral part to any hospital in the world. In recent times, health care industry has restructured its services to give better health care services to the study on patients. The focus of the study on patient' satisfaction from public hospitals services in selected cities Alkharj and Hotat Bani Tamim of Riyadh regions, Saudi Arabia. In these two public hospitals from each city, we conducted a sample of two hundred nineteen patients including hospitals representatives selected to collect primary data using Rasch measurement model, the measured items with the goodness fit and misfit of data. In the public hospitals services five items fulfilled the three stipulated criteria for misfit while two diagnosed as minor misfits. Patients' satisfaction from the two hospitals none of the items fulfilled the three stipulated criteria for misfit is due to varies of response from the respondents. The study shows that public hospitals are not performing well and hospitals services are inappropriate according to the needs of hospital representatives.
\end{abstract}

Keywords: patients' satisfaction, public hospital, representatives, Alkharj, Hotat Bani Tamim, services

\section{Introduction}

Hospital representatives seem indispensable to give better service in health care where good service is a pre-condition of systematic approach to deliver along with an environment or culture conducive to high standards. Patient satisfactions consider as important component in measuring health outcomes. The increasing strength of consumerism in society highlights the central role of patient's attitudes in health planning and delivery. Furthermore, a satisfied patient is more likely to develop a deeper and long lasting relationship with their health care provider, leading to improved compliance, continuity of care, and better health outcomes at large. To meet the patient's needs and to achieve the main goals of the health care system, it is essential to understand hospital representatives' attitudes in the hospitals of Alkharj and Hotat Bani Tamim, Saudi Arabia. Determinants of hospital services and patient satisfaction needed to investigate that reflected on the service quality of the hospitals. Thus, this research aimed at studying hospital representatives and their role in achieving patients' satisfaction using services of public hospitals in Saudi Arabia. The research will assist in assessing the practices and areas of satisfactions and the areas where the patients are dissatisfied.

\subsection{Statement of Problems}

The economy of Saudi Arabia is growing very fast. With the pace of reforms, the government of Saudi Arabia has focused on social sector such as education and health care system. The sudden increase in demand for healthcare services has exerted pressure on hospitals to meet new environmental challenges and bringing the quality of services in doubt leading to customer (patients) dissatisfaction. Previous studies reveal that over the years, Saudi Arabia is likely to increase sharply in its healthcare service needs. Researchers consider that population growth, a gradually aging society, and the conditions that affluence often exacerbates, such as obesity, diabetes, and heart diseases will create enormous new demand for healthcare services. Thus in the above situation, the present time is the appropriate time to measure the satisfaction of the patients to find out the areas to be focused for improvement in future. This study takes a step towards better understanding the factors responsible for patients' satisfaction and hospital representatives' skills to meet service quality, patients' need and satisfactions. 


\subsection{Study Objectives}

In this study, the authors aim at ascertaining the satisfaction level of patients using the services of public hospitals in selected cities Alkharj and Hotat Bani Tamim of Riyadh regions, Saudi Arabia. Ministry of Health emphasizes to pay attention to this important sector due to recent sudden increase in demand for health care services. Moreover, in presented research authors analyze competence of employees to give quality services to the patients and to find out the satisfaction level of the patients availing the services of public hospitals of Alkharj and Hotat Bani Tamim in Saudi Arabia.

\section{Literature Review}

Ware and Snyder (1975) examined the dimensions of patient attitudes regarding doctors and medical care services. The study described factor analytic development and validation of numerous index scores to measure patient attitudes regarding characteristics of doctors and medical care services. Four major dimensions of patient attitudes identified and described, including attitudes toward doctor conduct and such enabling components as availability of services, continuity/convenience of care and access mechanisms (cost, payment mechanisms, and ease of emergency care).

Mayer, Collier and Goldstein (1998) conducted the study to investigate the effect of clinically concentrated customer service training on patient satisfaction in the emergency department and trauma Centre. The research analyzed the patient complaints, patient compliments, and a statistically verified patient-satisfaction survey indicate that fourteen key quality aspects identified in the survey increased dramatically during study period .The advancement in the patient satisfaction survey came in ratings of skills of the emergency physician, likelihood of returning, skill of the emergency department nurse, and overall satisfaction. The findings showed clinically focused customer service training improves patient satisfaction and ratings of physician and nurse skills. The study suggested that such training might offer a substantial competitive market advantage and patients' perception of quality and outcome.

Andaleeb and Khandakar (2000) conducted a study to compare the quality of services provided by private and public hospitals in urban Bangladesh. The study used twenty-four scale items such as patient perceptions was sought on five aspects of service quality including responsiveness, assurance, communication, discipline and baksheesh (tip). Unlike private hospitals are not subsidized, during study realized that the incentive format would induce them to provide better services than public hospitals on the measures of service quality. The result showed both private and public have more scope for improvement.

Sohail (2003) examined the quality of services supported by private hospitals in Malaysia. Empirical research used to determine patients' expectations and perceptions of the quality of service and a comprehensive scale adapted from SERVQUAL analytically calculated for its usefulness in the hospital environment. The results of the study based on testing the mean differences between expectations and perception indicated that patients' perceived value of the services exceeded expectations for all the variables measured.

Marley, Collier and Goldstein (2004) investigated the quality service delivery from managers, clinical and process quality to patients. Causal model used with a sample of two hundred two hospitals in the United States. The result concluded hospital leadership has more influence on process quality than on clinical quality.

Andaleeb, Siddiqui and Khandakar (2007) conducted a study about patient satisfaction in government hospitals in Bangladesh over the quality of health care services in public, private and foreign hospitals, low utilization of public health facilities and growing outflow of Bangladeshi patients to hospitals in neighboring countries. A survey conducted including inpatients in public and private hospitals in the capital city Dhaka. Regression models used to identify important key factors. Poor quality of health services identified poor faith in hospital services.

Chilgren (2008) investigated the study of managers role toward quality is essential particularly the mid-level manager, has a vital role in the success of any healthcare hospitals especially in patient perception of quality. The quality can refer to as patient satisfaction. Managers with his team can develop quality processes geared toward patient expectations by doing a number of things, including the following: clearly identify outcomes, and empower employees to achieve those goals. With a successful quality program, managers can expect a considerable return on investment, satisfied patients and staff and possible improvement of clinical outcomes.

Almalki, Fitzgerald and Clark (2011) reviewed the current services of health care system in Saudi Arabia. The Study emphasized the public health challenges and opportunities in health care system. Such challenges are lack of professional medical staff, financial resources, high free medical service demand .Despite the comparison the ministry of Health generally improved health services at all level of health services. Ministry of Health 
introduced many reforms to improve the health system in Saudi Arabia.

Damnjanovic, Filipovic, Kostic, Novcic and Janicic (2011) analyzed a study to understand managers' attitude in health care organizations in Slovenia, Macedonia and Serbia with comparing their goals statement for internal and external perspective of patient attitude. The study conducted with three hundred managers in health care organizations in Slovenia, Macedonia and Serbia. The findings of the study suggested that health care managers should educated to adopt management practices of better adopting to environment changes improve their managerial skills for running a better health care organization.

Sreenivas and Babu (2012) observed the patient satisfaction in three samples hospitals in the states of Andhra Pradesh, India. Thirty-eight items and seven dimensions used in the study. Perceived quality identified at a range of facility types for patients. Only perceived quality is found favorable and need more scope for improvement. Better staff and physician relationships, availability of medicines, hospital infrastructure can improve the patient satisfaction in the sample hospitals of the study.

Based on the previous studies, the present study needs in order to understand better health services system in both cities of Riyadh region public hospitals in Alkharj and Hotat Bani Tamim cover main objectives of the study to help in to identify the services orientation of hospital representatives which may influence patients satisfactions in public hospitals.

\section{Method}

The total number of 310 questionnaires distributed and 219 responded questionnaires in this study with patients and hospital representatives from each public hospital in Alkharj and Hota Bani Tamim. Rasch Measurement Model (Fischer \& Linacre, 2007) measured the items designed in the questionnaires with goodness fit and misfit of data.

Rasch measurement model analysis applied to measure the relationship between hospital representatives and patients satisfactions from the both cities. A number of 36 items used to measure the satisfaction levels of 219 respondents and tested by using Rasch model. Evaluation of misfit and fit items suggest that the data demonstrated in the study. Fit analysis refers to logit scale, this model requires verification by looking OUTFIT column for mean square value, INFIT MNSQ $=\mathrm{y}, 0.5>\mathrm{y}<15$. This model emphasises if any item is larger MNSQ (mean square) than the sum of mean of IMNSQ(Item mean square) and SD (Standard deviation), than this gives an indication of high Z-STD(Z-Score), in this case 1.23 logit clearly indicates item misfit.

\section{Results}

\subsection{Overall Fit Analysis}

\subsubsection{Public Hospital Representatives Services of Alkharj and Hotat Bani Tamim}

The summary statistics, as shown in the Table 1, provide the goodness fit of the overall data. The person' Reliability Index was 0.95 with 4.25 Separation Index indicating that there were enough good items to differentiate person ability level. The further person fit statistics investigation on outfit for Mean-Square (OMNSQ) and Z-Score (OZSTD) showed that the OMNSQ was 1.04 and OZSTD was -0.80 , which were close to the expected values of 1 and 0 respectively. This also revealed that the 36 items were targeting the right type of respondents in measuring the latent traits and yielded data at a reasonable prediction level of the responses to the items. The maximum person ability was $\delta_{\max }=+5.55$ logit and the minimum measure was $\delta_{\min }=-1.66$ logit . The length of the logit scale was 7.21logit. The Organisation Mean, $\delta_{\text {mean }}=0.00$ logit revealed that the majority of the organisations found it relatively easy to endorse the items. This suggests that the people spread adequately into three groups across the items and the trait continuum.

As shown in Table 1 , the Item Reliability was $\beta_{\text {item }}=0.91$ with suggesting that the instrument had a good fit with the model. The high item reliability also indicated that the replicability of the items would occur if these items given to another sample of respondents of the same size. As for the Item Mean, it was set at $\mu_{\text {mean }} 0.00$ logit to ensure that each organisation had a 50:50 chance of success in responding to the item that matched their ability. The OMNSQ was 1.04 and OZSTD was -0.10 , which were close to the expected values of 1 and 0 respectively. This also revealed that most of the items targeted the organisation distribution, which meant an excellent targeting of the items to organisations. The maximum item ability was $\beta_{\max }=+1.52 \operatorname{logit}$ and the minimum measure was $\mu_{\min }=-1.71$ logit. The length of the logit scale was 3.23 logit. The separation statistic for items was 3.10 , indicating that the 36 items were generally separated into four groups. 
Table 1. Public Hospital Representatives Services of Alkharj and Hotat Bani Tamim

\begin{tabular}{|c|c|c|}
\hline & 58 measured person & 36 measured item \\
\hline Reliability & 0.95 & 0.91 \\
\hline Separation Index & 4.25 & 3.10 \\
\hline Mean & 1.51 & 0.00 \\
\hline S.D. & 1.57 & 0.71 \\
\hline Max. & 5.55 & 1.52 \\
\hline Min. & -1.66 & -1.71 \\
\hline Outfit MNSQ & 1.04 & 1.04 \\
\hline Outfit ZSTD & -0.80 & -0.10 \\
\hline S.E & 0.21 & 0.12 \\
\hline Cronbach Alpha (Kr-20) & \multicolumn{2}{|c|}{0.97} \\
\hline Raw variance explained by measures & \multicolumn{2}{|c|}{$54.3 \%$} \\
\hline Unexplained variance explained by measures & \multicolumn{2}{|c|}{$45.7 \%$} \\
\hline Unexplained variance in 1 st contrast & \multicolumn{2}{|c|}{$6.4 \%$} \\
\hline
\end{tabular}

To ensure proper construct validity, the Principal Components Analysis (PCA) was performed to assess residual variance for the 36 measured items. The results of PCA show that the raw variance explained by measures of $54.3 \%$ and it fulfilled minimum raw variance explained by measures as proposed by Fischer (2007) and Linacre (2007). The Raw unexplained variance by measures is $45.7 \%$ and unexplained variance in the first contrast of $6.4 \%$, rated the instrument as good (Fischer, 2007) and show it unidimensional. In overall, this resulted in a 36-item in measuring the hospital representatives satisfaction of healthcare services in public hospitals in Alkharj and Hotat Bani Tamim, Saudi Arabia which was shown to be unidimensional with good internal consistency.

\subsubsection{Item Fit Analysis}

Item fit analysis conducted in assessing how well the items fitted the Rasch Model. Items regarded as misfits when they do not measure the variable accordingly and provide a distorted representation of the data. Keeping these misfit items would not be advantageous, and considered as a threat to validity. In Rasch Measurement Model, the items considered misfits when they fulfil the following three criteria:

- Outfit MNSQ - item should be accepted if it is within 0.5-1.5

- Outfit ZSTD - item should be accepted if it is within the range of $+/-2$

- Point to Measure Correlation - item should be accepted if it is within the range of $0.30-0.80$

Based on the aforementioned criteria, Table 2 shows that none of the items fulfilled the three stipulated criteria for misfit. However, seven items diagnosed as minor misfit.

1. a1- the goals of our hospital the best describe as right attitude towards patients

2. a3-the goal of our hospital is to become one of the most competent hospital

3. c1-managers in hospital always act and react in ethical manner

4. c13-we have all the resources needed to perform the job are provided

5. c8-always provide enough information by the hospital to the job well

6. $c 9$-hospital is easily managed by the director/manager of the hospitaland

7. $\quad b 8$-always provide enough information by the hospital to the job well

The minor misfit is due to varies of response pattern from the respondents. Nevertheless, they were still at an acceptable range since, when referring vertically to Outfit MNSQ, Outfit ZSTD and Point Measure Correlation, all were within an accepted range. Thus, these items retained for further analysis. Overall, the statistics for fit analysis criteria of the items were in the following range:

- Measure $=-0.71 \operatorname{logit}>\mathrm{x}<1.52$ logit

- $\quad$ Model SE $=0.18>\mathrm{x}<0.25$

- Outfit MNSQ $=0.38>\mathrm{x}<2.98$ 
- $\quad$ Outfit ZSTD = $-3.90>\mathrm{x}<7.10$

- Point Measure Correlation $=0.52>\mathrm{x}<0.81$

Table 2. Item misfit order

\begin{tabular}{|c|c|c|c|c|c|c|c|}
\hline S.N & Item & MEASURE & S.E. & MNSQ & ZSTD & Point Measure Correlation & Remarks \\
\hline & a1 & 1.52 & 0.18 & 2.98 & 7.10 & 0.52 & Minor Misfit \\
\hline & $\mathrm{c} 1$ & 1.30 & 0.18 & 2.77 & 6.50 & 0.53 & Minor Misfit \\
\hline & $\mathrm{c} 13$ & 0.79 & 0.19 & 2.75 & 6.30 & 0.53 & Minor Misfit \\
\hline & a3 & 0.28 & 0.20 & 0.51 & -3.00 & 0.77 & Minor Misfit \\
\hline & c8 & 0.00 & 0.20 & 0.50 & -3.00 & 0.76 & Minor Misfit \\
\hline & c9 & -0.04 & 0.20 & 0.48 & -3.10 & 0.77 & Minor Misfit \\
\hline & b8 & -0.12 & 0.20 & 0.38 & -3.90 & 0.81 & Minor Misfit \\
\hline & b5 & 0.35 & 0.20 & 1.37 & 1.70 & 0.60 & Normal \\
\hline & b15 & -0.04 & 0.20 & 1.11 & 0.60 & 0.72 & Normal \\
\hline & $\mathrm{c} 2$ & -1.47 & 0.24 & 1.21 & 0.80 & 0.55 & Normal \\
\hline & b17 & 0.68 & 0.19 & 1.26 & 1.30 & 0.70 & Normal \\
\hline & b4 & -0.99 & 0.22 & 1.18 & 0.80 & 0.58 & Normal \\
\hline & b12 & -0.99 & 0.22 & 1.08 & 0.40 & 0.62 & Normal \\
\hline & b18 & 0.35 & 0.19 & 1.13 & 0.70 & 0.65 & Normal \\
\hline & c3 & -0.12 & 0.20 & 1.07 & 0.40 & 0.70 & Normal \\
\hline & b3 & -0.25 & 0.21 & 1.03 & 0.20 & 0.63 & Normal \\
\hline & $\mathrm{c} 12$ & -0.47 & 0.21 & 1.05 & 0.30 & 0.62 & Normal \\
\hline & b1 & 0.68 & 0.19 & 1.04 & 0.30 & 0.74 & Normal \\
\hline & c7 & -1.09 & 0.23 & 1.02 & 0.20 & 0.58 & Normal \\
\hline & b9 & 0.39 & 0.19 & 1.02 & 0.20 & 0.73 & Normal \\
\hline & b14 & -0.99 & 0.22 & 0.90 & -0.40 & 0.67 & Normal \\
\hline & b7 & -0.47 & 0.21 & 0.86 & -0.60 & 0.65 & Normal \\
\hline & b11 & -0.12 & 0.20 & 0.93 & -0.30 & 0.71 & Normal \\
\hline & b10 & 0.47 & 0.19 & 0.96 & -0.10 & 0.72 & Normal \\
\hline & c6 & 0.35 & 0.19 & 0.85 & -0.70 & 0.73 & Normal \\
\hline & c4 & 0.72 & 0.19 & 0.87 & -0.60 & 0.74 & Normal \\
\hline & b16 & 0.04 & 0.20 & 0.85 & -0.70 & 0.73 & Normal \\
\hline & b2 & 0.10 & 0.20 & 0.74 & -1.30 & 0.76 & Normal \\
\hline & $\mathrm{c} 5$ & 0.12 & 0.20 & 0.83 & -0.80 & 0.69 & Normal \\
\hline & b13 & -1.71 & 0.25 & 0.70 & -1.00 & 0.64 & Normal \\
\hline & a5 & 0.68 & 0.19 & 0.79 & -1.10 & 0.75 & Normal \\
\hline & $\mathrm{a} 4$ & 0.54 & 0.19 & 0.76 & -1.30 & 0.73 & Normal \\
\hline & b6 & -0.08 & 0.20 & 0.69 & -1.60 & 0.71 & Normal \\
\hline & a2 & -0.60 & 0.21 & 0.64 & -1.80 & 0.70 & Normal \\
\hline & $\mathrm{c} 11$ & -0.16 & 0.20 & 0.59 & -2.30 & 0.74 & Normal \\
\hline & $\mathrm{c} 10$ & 0.32 & 0.20 & 0.59 & -2.40 & 0.77 & Normal \\
\hline
\end{tabular}


Table 3. Public Hospital Representatives' Services in AlKharj and Hotat Bani Tamim

\begin{tabular}{|c|c|c|c|c|}
\hline S.N & Code & Measure & S.E. & Dissatisfied Items \\
\hline 1. & a1 & 1.52 & 0.18 & The goals of our hospital are best described as having right attitude towards patients \\
\hline 2. & c2 & 1.30 & 0.18 & $\begin{array}{l}\text { Mangers/Supervisors of the hospital tells when doing well \& give enough authority } \\
\text { to carry out work for patient satisfaction }\end{array}$ \\
\hline 3. & c14 & 0.79 & 0.19 & $\begin{array}{l}\text { Introducing a new program to improve patient satisfaction in your hospital is the } \\
\text { main reason for possibility of losing patient satisfaction and possibility of loss of } \\
\text { reputation in the region. }\end{array}$ \\
\hline 4. & $\mathrm{c} 5$ & 0.72 & 0.19 & Clarity in communication of policies \& procedures \\
\hline 5. & a5 & 0.68 & 0.19 & Our hospital have mission and strategic goals \\
\hline 6. & b1 & 0.68 & 0.19 & There is a clarity of administrative procedures of hospital \\
\hline 7. & b17 & 0.68 & 0.19 & If patient satisfaction survey starts for health care services. Will it work effectively? \\
\hline 8. & a4 & 0.54 & 0.19 & We understand the long-term plan of hospital \\
\hline 9. & b10 & 0.47 & 0.19 & $\begin{array}{l}\text { Hospital emphasizes competitive actions and achievement and measurable goals are } \\
\text { important }\end{array}$ \\
\hline 10. & b9 & 0.39 & 0.19 & $\begin{array}{l}\text { Hospital emphasizes growth and acquiring new resources and readiness to meet } \\
\text { new challenges }\end{array}$ \\
\hline 11. & $\mathrm{c} 1$ & 0.35 & 0.19 & Managers in Hospital always act \& react in ethical manner \\
\hline 12. & c7 & 0.35 & 0.19 & Relationship with the supervisor and manager \\
\hline 13. & b5 & 0.35 & 0.20 & Hospital maintain electronic data base of patients \\
\hline 14. & $\mathrm{c} 11$ & 0.32 & 0.20 & Junior medical staff share the latest development in medical fields \\
\hline 15. & a3 & 0.28 & 0.20 & The goals of our hospital is to become one of the most competent hospital. \\
\hline 16. & c6 & 0.12 & 0.20 & There is trust between employees and their supervisors \\
\hline 17. & b2 & 0.10 & 0.20 & Response of administration to problems and suggestions \\
\hline 18 & b16 & 0.04 & 0.20 & Employees are rewarded for providing high quality services to patient. \\
\hline 19. & c9 & 0.00 & 0.20 & $\begin{array}{l}\text { Hospital is easily managed by the director or manager of the hospital } \\
\text { Satisfied Items }\end{array}$ \\
\hline 20. & b15 & -0.04 & 0.20 & Environment of hospital is encouraging and stimulating to work \\
\hline 21. & $\mathrm{c} 10$ & -0.04 & 0.20 & Always use medical terms with explaining to patients for diagnosis \\
\hline 22. & b6 & -0.08 & 0.20 & Management has clarity of Administrative Procedures of Hospital \\
\hline 23. & b8 & -0.12 & 0.20 & They always provide enough information by the hospital to the job well \\
\hline 24. & b11 & -0.12 & 0.20 & $\begin{array}{l}\text { Introducing a new program to improve patient satisfaction in your hospital is the } \\
\text { main reason for possibility of losing patient satisfaction and possibility of loss of } \\
\text { reputation in the region. }\end{array}$ \\
\hline 25 . & $\mathrm{c} 4$ & -0.12 & 0.20 & They give us enough authority to make decisions \\
\hline 26. & $\mathrm{c} 12$ & -0.16 & 0.20 & $\begin{array}{l}\text { Hospital management needs to do more for patient' satisfaction of health care } \\
\text { services in hospital. }\end{array}$ \\
\hline 27. & b3 & -0.25 & 0.21 & Receive speedy feedback from authorities \\
\hline 28. & b7 & -0.47 & 0.21 & Initial training was provided by the hospital as needed \\
\hline 29. & c13 & -0.47 & 0.21 & We have all the resources needed to perform the job are provided \\
\hline 30. & a2 & -0.60 & 0.21 & The goals of our hospital are best described as achieving patient satisfaction. \\
\hline 31. & b4 & -0.99 & 0.22 & Give enough authority to make decisions \\
\hline 32. & b12 & -0.99 & 0.22 & $\begin{array}{l}\text { Hospital management needs to do more for patient' satisfaction of health care } \\
\text { services in your hospital. }\end{array}$ \\
\hline 33. & b14 & -0.99 & 0.22 & They always follow the guidelines of Ministry of health \\
\hline 34. & $\mathrm{c} 8$ & -1.09 & 0.23 & Always provide enough information by the hospital to the job well \\
\hline 35 . & c3 & -1.47 & 0.24 & Communication from top management always keep up to date \\
\hline 36. & b13 & -1.71 & 0.25 & Resources needed to perform the job are provided \\
\hline
\end{tabular}




\subsubsection{Overall Fit Analysis-Patients' Satisfaction from Public Hospitals in Alkharj and Hotat Bani Tamim}

The collected primary data showed to be reliable in the summary statistics, as shown in the Table 4, provide the goodness fit of the overall data. The person' Reliability Index was 0.96 with 4.99 Separation Index indicating that there were enough good items to differentiate person ability level. The further person fit statistics investigation on outfit for Mean-Square (OMNSQ) and Z-Score (OZSTD) showed that the OMNSQ was 1.21 and OZSTD was -0.40 , which were close to the expected values of 1 and 0 respectively. Revealed that the 36 items were targeting the right type of respondents in measuring the latent traits and yielded data at a reasonable prediction level of the responses to the items. The maximum person ability was $\delta_{\max }=+5.25$ logit and the minimum measure was $\delta_{\min }=-5.24$ logit. The length of the logit scale was 10.49logit. The Organisation Mean, $\delta_{\text {mean }}=0.03$ logit revealed that the majority of the organisations found it relatively easy to endorse the items. This suggests that the respondents spread adequately into three groups across the items and the trait continuum.

Table 4. Patients' satisfaction-Public Hospitals in Alkharj and Hotat Bani Tamim

\begin{tabular}{|c|c|c|}
\hline & 161 measured person & 36 measured item \\
\hline Reliability & 0.96 & 0.90 \\
\hline Separation Index & 4.99 & 3.06 \\
\hline Mean & 0.03 & 0.00 \\
\hline S.D. & 2.09 & 0.34 \\
\hline Max. & 5.25 & 0.64 \\
\hline Min. & -5.24 & -0.79 \\
\hline Outfit MNSQ & 1.21 & 1.09 \\
\hline Outfit ZSTD & -0.40 & -0.08 \\
\hline S.E & 0.17 & 0.06 \\
\hline Cronbach Alpha (Kr-20) & \multicolumn{2}{|c|}{0.99} \\
\hline Raw variance explained by measures & \multicolumn{2}{|c|}{$67.7 \%$} \\
\hline Unexplained variance explained by measures & \multicolumn{2}{|c|}{$32.3 \%$} \\
\hline Unexplained variance in 1 st contrast & \multicolumn{2}{|c|}{$3.4 \%$} \\
\hline
\end{tabular}

As given in Table 4, the Item Reliability was $\beta_{\text {item }}=0.90$ with recommending that the instrument had a good fit with the model. The high item reliability also indicated that the replicability of the items would occur if these items given to another sample of respondents of the same size. As for the Item Mean, it was set at $\mu_{\text {mean }} 0.00$ logit to ensure that each organisation had a 50:50 chance of success in responding to the item that matched their ability. The OMNSQ was 1.09 and OZSTD was -0.08 , which were close to the expected values of 1 and 0 respectively. It also revealed that most of the items targeted the organisation distribution, which meant an excellent targeting of the items to organisations. The maximum item ability was $\beta_{\max }=+0.64$ logit and the minimum measure was $\mu_{\min }=-0.08$ logit. The length of the logit scale was 1.17 logit. The separation statistic for items was 3.06, indicating that the 36 items were generally separated into four groups.

To ensure proper construct validity, the Principal Components Analysis (PCA) performed to assess residual variance for the 36 measured items. The results of PCA show that the raw variance explained by measures of $67.7 \%$ and it fulfilled minimum raw variance explained by measures as proposed by Fischer (2007) and Linacre (2007). The Raw unexplained variance by measures is $32.3 \%$ and unexplained variance in the first contrast of $6.4 \%$, rated the instrument as good (Fischer, 2007) and show it unidimensional. In overall, this resulted in a 36-item in measuring the hospital representatives for patients satisfaction of healthcare services in public hospitals in Alkharj and Hotat Bani Tamim, Saudi Arabia which was shown to be unidimensional with good internal consistency.

\subsubsection{Organization Misfit Analysis}

The summary statistics in the Table 4 shows that some aspects do not conform to the required value. Hence, the identification of misfit Organisations was necessary to ensure that all respondents fit to model. This process is important because the 'misfit Organisations' agreeability on the items may not be appropriately measured by the 
instrument. The misfit organisations known as unusual responses. After the process of identification of misfit Organisations, the analysis of the Organisations statistics revealed that out of 44 Organisations, 11 Organisations exhibited as misfit Organisations. This indicates that these Organisations could not have their perceptions precisely measured by the items used to measure the potential of clients' organisation towards implementing BIM. Finally, the fit Organisations with Rasch measurement model were at 33, indicating a goodness-of-fit to measure the potential of the clients' organisation towards implementing BIM.

Table 5. Patient' satisfaction of public hospitals in Alkharj and Hotat Bani Tamim

\begin{tabular}{|c|c|c|}
\hline & $\begin{array}{l}\text { Before identifying misfit } \\
\text { Organisation }(\mathrm{n}=44)\end{array}$ & $\begin{array}{l}\text { After identifying misfit } \\
\text { Organisation }(\mathrm{n}=33)\end{array}$ \\
\hline Cronbach's alpha $(\alpha)$ & 0.99 & 0.99 \\
\hline \multicolumn{3}{|l|}{ Organisation } \\
\hline Reliability Index & 0.96 & 0.97 \\
\hline Separation Index & 4.99 & 5.57 \\
\hline Mean & 0.03 & 0.31 \\
\hline S.D & 2.09 & 2.05 \\
\hline Max & 5.25 & 5.48 \\
\hline Min & -5.24 & -4.84 \\
\hline \multicolumn{3}{|l|}{ Item } \\
\hline Reliability Index & 0.90 & 0.94 \\
\hline Separation Index & 3.06 & 3.88 \\
\hline Mean & 0.00 & 0.00 \\
\hline S.D & 0.34 & 0.49 \\
\hline $\operatorname{Max}$ & 0.64 & 0.95 \\
\hline Min & -0.79 & -1.13 \\
\hline \multicolumn{3}{|l|}{ Standardized Residual Variance } \\
\hline Raw variance explained by measures & $67.7 \%$ & $67.9 \%$ \\
\hline Unexplained variance in $1^{\text {st }}$ contrast & $32.3 \%$ & $32.1 \%$ \\
\hline Unexplained variance in 1 st contrast & $3.4 \%$ & $3.4 \%$ \\
\hline
\end{tabular}

After the person misfit have been identified, it is important to analyse the results of the summary statistics to see if better results could be obtained compared to before the identification of person misfit, or vice versa. As shown in the Table 5, the value of Cronbach's alpha was at 0.99 , which is same than before and considered to have a good reliability in measuring patients satisfaction of public hospitals in Alkharj and Hotat Bani Tamim, Saudi Arabia. Apart from that, person reliability was higher (0.97) compared to before (0.96) which denotes excellent reliability. Furthermore, person separation was higher than before at 5.57. This indicates that the assessment of demographic information can discriminate between the organisation's capability and difficulty of the task. The Raw Variance explained by measures also higher at $67.9 \%$ and unexplained variance in 1 st contrast was lower after at the $32.1 \% \%$. Thus, the analysis highlights that the measurement instrument used to measure hospital representatives' services for patients satisfaction of healthcare services in public hospital in Alkharj and Hota Bani Tamim, Saudi Arabia was reliable and valid and formed a good measurement.

\subsubsection{Item Fit Analysis}

Item fit analysis organized in assessing how well the items fitted the Rasch Model. Items considered as misfits when they do not measure the variable accordingly and provide a distorted representation of the data. Observing these misfit items would not be beneficial, and considered as a threat to validity. In Rasch Measurement Model, 
the items treated misfits when they fulfil the following three criteria:

- Outfit MNSQ - item should be accepted if it is within 0.5-1.5

- Outfit ZSTD - item should be accepted if it is within the range of $+/-2$

- Point to Measure Correlation - item should be accepted if it is within the range of $0.30-0.80$

Table 6. Item Misfit Order

\begin{tabular}{|c|c|c|c|c|c|c|}
\hline \multirow{2}{*}{ S.N } & \multirow{2}{*}{ Item } & \multirow{2}{*}{ Model S.E } & \multicolumn{2}{|c|}{ OUTFIT } & \multirow{2}{*}{ Point Measure Correlation } & \multirow{2}{*}{ Remarks } \\
\hline & & & MNSQ & ZSTD & & \\
\hline 1 & d6 & 0.11 & 5.38 & 9.90 & 0.51 & Minor Misfit \\
\hline 2. & $\mathrm{c} 7$ & 0.11 & 1.91 & 4.10 & 0.76 & Minor Misfit \\
\hline 3. & $\mathrm{c} 4$ & 0.12 & 1.54 & 2.10 & 0.67 & Minor Misfit \\
\hline 4. & a7 & 0.11 & 0.93 & -0.40 & 0.81 & Minor Misfit \\
\hline 5. & a1 & 0.12 & 0.91 & -0.40 & 0.81 & Minor Misfit \\
\hline 6. & $\mathrm{c} 12$ & 0.11 & 0.79 & -1.30 & 0.81 & Minor Misfit \\
\hline 7. & $\mathrm{c} 2$ & 0.11 & 0.72 & -1.70 & 0.82 & Minor Misfit \\
\hline 8. & $\mathrm{c} 1$ & 0.12 & 0.73 & -1.60 & 0.82 & Minor Misfit \\
\hline 9. & a8 & 0.12 & 0.77 & -1.30 & 0.81 & Minor Misfit \\
\hline 10. & $\mathrm{c} 13$ & 0.11 & 0.70 & -1.90 & 0.83 & Minor Misfit \\
\hline 11. & a11 & 0.11 & 0.65 & -2.30 & 0.84 & Minor Misfit \\
\hline 12. & b6 & 0.11 & 0.61 & -2.50 & 0.83 & Minor Misfit \\
\hline 13. & $\mathrm{a} 6$ & 0.12 & 0.64 & -2.10 & 0.83 & Minor Misfit \\
\hline 14. & c9 & 0.11 & 0.61 & -2.40 & 0.84 & Minor Misfit \\
\hline 15. & $\mathrm{a} 4$ & 0.12 & 0.62 & -2.30 & 0.84 & Minor Misfit \\
\hline 16. & $\mathrm{c} 8$ & 0.11 & 0.58 & -2.70 & 0.85 & Minor Misfit \\
\hline 17. & b5 & 0.12 & 0.50 & -3.30 & 0.86 & Minor Misfit \\
\hline 18. & $\mathrm{c} 10$ & 0.12 & 1.14 & 0.80 & 0.74 & Normal \\
\hline 19. & $\mathrm{~d} 1$ & 0.11 & 1.11 & 0.60 & 0.76 & Normal \\
\hline 20. & $\mathrm{c} 11$ & 0.11 & 1.09 & 0.60 & 0.77 & Normal \\
\hline 21. & $\mathrm{c} 5$ & 0.11 & 1.12 & 0.70 & 0.76 & Normal \\
\hline 22. & a9 & 0.11 & 1.00 & 0.10 & 0.77 & Normal \\
\hline 23. & $\mathrm{~d} 4$ & 0.11 & 0.96 & -0.10 & 0.78 & Normal \\
\hline 24. & $\mathrm{a} 10$ & 0.11 & 0.95 & -0.30 & 0.79 & Normal \\
\hline 25. & $\mathrm{a} 2$ & 0.11 & 1.11 & 0.70 & 0.77 & Normal \\
\hline 26. & c6 & 0.11 & 0.99 & 0.00 & 0.79 & Normal \\
\hline 27. & b3 & 0.12 & 0.99 & 0.00 & 0.77 & Normal \\
\hline 28. & $\mathrm{~d} 2$ & 0.11 & 0.99 & 0.00 & 0.76 & Normal \\
\hline 29. & $\mathrm{~b} 2$ & 0.11 & 0.88 & -0.70 & 0.79 & Normal \\
\hline 30. & $\mathrm{c} 3$ & 0.11 & 0.91 & -0.50 & 0.78 & Normal \\
\hline 31. & $\mathrm{~b} 4$ & 0.11 & 0.91 & -0.50 & 0.79 & Normal \\
\hline 32. & $\mathrm{~d} 3$ & 0.11 & 0.85 & -0.80 & 0.80 & Normal \\
\hline 33. & a5 & 0.11 & 0.80 & -1.10 & 0.79 & Normal \\
\hline 34. & $\mathrm{a} 3$ & 0.12 & 0.91 & -0.40 & 0.80 & Normal \\
\hline 35. & $\mathrm{~d} 5$ & 0.11 & 0.79 & -1.20 & 0.80 & Normal \\
\hline 36. & $\mathrm{~b} 1$ & 0.11 & 0.69 & -1.90 & 0.83 & Normal \\
\hline
\end{tabular}


Based on the aforementioned criteria, The Table 6 shows that none of the items fulfilled the three stipulated criteria for misfit. However, the following seventeen items as minor misfit.

1. d6-there is health care crisis in government hospitals in Saudi Arabia

2. c7-some time on request doctor treat me attentively

3. c4-receive more information about me and family members condition or treatment,

4. a7-doctor ask about family history before treatment

5. a1-doctor is always willing to answer my question

6. c12-If complain general manager of the hospital give fair treatment,

7. c2-admission process is easy

8. c1-prior treatment can easily access the specialist

9. a8-the doctors of this hospital are qualified

10. c13-coordination and communication between general manger,administrative staff doctors ,nurses and paramedical staff is good

11. all-overall the attitude of doctors of this hospital is satisfactory

12. b6-security manager of this hospital is very dedicated and cooperative

13. a6-doctor give appropriate advice for prescriptions

14. c9-physical environment and services are good

15. a4-doctors explain the purpose of diagnostic test

16. c8- hospital provide me full information about the hospital

17. b5- medical staff treat me knows about the medical development.

The minor misfit is due to varies of response pattern from the respondents. Nevertheless, they were still at an acceptable range since, when referring vertically to Outfit MNSQ, Outfit ZSTD and Point Measure Correlation, all were within an accepted range. Thus, these items retained for further analysis. Overall, the statistics for fit analysis criteria of the items were in the following range:

- Measure $=-1.13$ logit $>\mathrm{x}<0.95$ logit

- Model SE $=0.01>\mathrm{x}<0.12$

- $\quad$ Outfit MNSQ $=0.50>\mathrm{x}<5.38$

- Outfit ZSTD $=-3.30>\mathrm{x}<9.90$

- $\quad$ Point Measure Correlation $=0.51>\mathrm{x}<0.86$

Table 7. Patient satisfaction of public hospitals in Alkharj and Hotat Bani Tamim

\begin{tabular}{ccccl}
\hline S.N & Code & Measure & Model S.E & Dissatisfied Items \\
\hline 1. & $\mathrm{~d} 6$ & 0.95 & 0.11 & There is health care crisis in government hospitals in Saudi Arabia \\
2. & $\mathrm{d} 3$ & 0.9 & 0.11 & Operation theatre and equipment are available \\
3. & $\mathrm{c} 9$ & 0.81 & 0.11 & Physical environment and services are good \\
4. & $\mathrm{c} 8$ & 0.72 & 0.11 & Hospital provide me full information about the hospital \\
5. & $\mathrm{~d} 1$ & 0.68 & 0.11 & Waiting room is comfortable and pleasant \\
6. & $\mathrm{c} 7$ & 0.55 & 0.11 & Some time on request doctor treat me attentively \\
7. & $\mathrm{~d} 4$ & 0.49 & 0.11 & Emergency is well equipped and services are prompt \\
8. & $\mathrm{~d} 2$ & 0.4 & 0.11 & Health care centres are well equipped \\
9. & $\mathrm{c} 13$ & 0.36 & 0.11 & $\begin{array}{l}\text { Coordination and communication between general manger } \\
\text { administrative staff, doctors, nurses and paramedical staff is good }\end{array}$ \\
10. & $\mathrm{c} 6$ & 0.3 & 0.11 & Before given new medicine, hospital staff tell about the medicine
\end{tabular}




\begin{tabular}{|c|c|c|c|c|}
\hline S.N & Code & Measure & Model S.E & Dissatisfied Items \\
\hline 11. & a10 & 0.25 & 0.11 & Always happy to see the same doctor who treated me in my prior visit \\
\hline 12. & a7 & 0.23 & 0.11 & Doctor ask about family history before treatment \\
\hline 13. & a11 & 0.17 & 0.11 & Overall the attitude of doctors of this hospital is satisfactory \\
\hline 14. & $\mathrm{c} 12$ & 0.17 & 0.11 & If complain, General manager of the hospital giver fair treatment \\
\hline 15. & $\mathrm{c} 5$ & 0.08 & 0.11 & Receive free medicine \\
\hline 16. & b1 & 0.05 & 0.11 & Nurses and paramedical staff are caring \\
\hline 17. & b6 & 0.05 & 0.11 & $\begin{array}{l}\text { Security manager of this hospital is very dedicated and cooperative } \\
\text { Satisfied Items }\end{array}$ \\
\hline 18. & c2 & -0.05 & 0.11 & Admission process is easy \\
\hline 19. & d5 & -0.08 & 0.11 & Over all Hospital, its staff services, and level of care is satisfactory \\
\hline 20. & b2 & -0.14 & 0.11 & Nurses and paramedical staff give proper attention \\
\hline 21. & a5 & -0.17 & 0.11 & Doctor listens me attentively \\
\hline 22. & c3 & -0.17 & 0.11 & Easy to get choice of admission date \\
\hline 23. & a2 & -0.18 & 0.11 & Doctors are caring \\
\hline 24. & c11 & -0.18 & 0.11 & Doctors and supporting staff are neat and clean in appearance \\
\hline 25. & a9 & -0.27 & 0.11 & The doctors of this hospital is competent \\
\hline 26. & b4 & -0.27 & 0.11 & Staff at the registration counter are helpful and cooperative \\
\hline 27. & $\mathrm{c} 1$ & -0.31 & 0.12 & Prior treatment I can easily access the specialist \\
\hline 28. & a8 & -0.35 & 0.12 & The doctors of this hospital are qualified \\
\hline 29. & $\mathrm{c} 10$ & -0.36 & 0.12 & Hospital building and premises are neat and clean \\
\hline 30. & a3 & -0.47 & 0.12 & Doctor is always available on appointment date \\
\hline 31. & b5 & -0.5 & 0.12 & Medical staff who treat me knows about the medical development \\
\hline 32. & $\mathrm{a} 4$ & -0.54 & 0.12 & Doctors explain the purpose of diagnostic test \\
\hline 33. & a1 & -0.55 & 0.12 & Doctor is always willing to answer my question \\
\hline 34. & a6 & -0.62 & 0.12 & Doctor give appropriate advice for prescriptions \\
\hline 35. & b3 & -0.82 & 0.12 & Nurses and staff treat properly as per doctor instructions \\
\hline 36. & $\mathrm{c} 4$ & -1.13 & 0.12 & $\begin{array}{l}\text { Receive more information about me and family members condition or } \\
\text { treatment }\end{array}$ \\
\hline
\end{tabular}

Items clearly indicate the high dissatisfactions and satisfaction items in the study hospital representatives services and hospitals towards patients' satisfactions. Hospitals representatives found to be satisfactory in their orientation while hospitals infrastructure and basic medical services are not satisfactory especially Hotat Bani Tamim city public hospital. This city considered as weak compared to Alkharj city in terms of population, infrastructure and services.

\section{Conclusion}

Based on this comparative study the overall, result in thirty-six items in measuring public hospitals representative services of the two selected cities for the study shown to be unidimensional with good internal consistency, the analysis highlights that the measurement instrument used to measure patients' satisfaction was reliable and validated formed a good instrument. Therefore, the result shows the patients' satisfaction from the two hospitals is poor and they are dissatisfied ranges from the seventeen items (Table 6).On the other hand, service quality is inappropriate according to the need of hospitals representatives' ranges from the seven items (Table 2). Based on the study results, the study indicates high dissatisfaction of both hospitals services at local levels. It is highly recommended to improve the satisfaction levels at Public hospital of Alkharj and Hotat Bani Tamim- 
1. The hospitals should provide regular training and orientation programme to their staff for professional development.

2. Both hospital have patients' complains and grievances counters for effective communications.

3. Hospitals should have proper medical and health infrastructure and proper availability of medical equipment for emergency.

4. Hospitals need to avoid unnecessary medical practices for medication and long procedures.

5. Hospital especially Hota Bani Tamim needs to pay more attentions to basic services without fail, which observed by regular hospital patients.

6. Comprehensive study at national level needed on urgent basis to improve the public hospital services.

\section{Acknowledgments}

Authors of the study would like to extend their gratitude towards the project funded by Deanship of Scientific Research, Prince Sattam bin Abdulaziz University (PSAU), Saudi Arabia.

\section{References}

Andaleeb, S. S. (2000). Service quality in public and private hospitals in urban Bangladesh: A comparative study. Health Policy, 53(1), 25-37. http://dx.doi.org/10.1016/S0168-8510(00)00077-4

Andaleeb, S. S., Siddiqui, N., \& Khandakar, S. (2007). Patient satisfaction with health services in Bangladesh. Health Policy Plan, (22), 263-273. http://dx.doi.org/10.1093/heapol/czm017

Avali, J. (2008). The role of quality improvement initiatives in healthcare operational environments. International Journal of Health Care Quality Assurance, 21(2), 135-145.

Chilgren, A. A. (2008). Managers and the new definition of quality. Journal of Health care Management, 53(4), 221-230.

Damnjanovic, V., Filipovic, V., Kostic, S. C., Novcic, B., \& Janicic, R. (2011). Manager orientation of health care organization-comparison study of Serbia, Macedonia and Slovenia. Health Med, 5(6), 2206-2213.

Fischer, W. P. (2007). Rasch measurement and the R statistics environment. Rasch measurement transaction, 21(1), 1087.

Fitzgerald, A. M., Clark, G. (2011). Health care system in Saudi Arabia: an overview. Eastern Mediterranean Health Journal, 17(10), 784-793.

Linacre, J. M. (2007). Rasch fit and Serendipity. Rasch measurement transaction, 20(4), 1076.

Marley, K. A., Collier, A. D., \& Goldstein, M. S. (2004). The role of clinical and process quality in achieving patient satisfaction in hospitals. Decision Sciences, 35(3), 349-369. http://dx.doi.org/10.1111/j.00117315.2004.02570.x

Mayer, T. A., Cates, R. J., Mastorovich, M. J., \& Royalty, D. L. (1998). Emergency department patient satisfaction: Customer service training improves patient satisfaction and ratings of physician and nurse skill. Journal of Healthcare Management, 43(5), 427-442.

Rasch, G. (1960). Probabilistic models for some intelligence and attainment (Copenhagen, Danish institute for education research). The University of Chicago Press.

Sohail, S. M. (2003). Service quality in hospitals more favorable than you might think. Managing Service Quality (Emerald MCD), 13(3), 197-206. http://dx.doi.org/10.1108/09604520310476463

Sreenivas, T. B. (2012). A study on patient satisfaction in hospital. Intl. J. Mgmt. Res \& Bus.Strat, 1(1), 101-118.

Ware, J. E., \& Snyder, M. K. (1975). Dimensions of patient attitudes regarding doctors and medical care service. Medical Care, 8(8), 669-682. http://dx.doi.org/10.1097/00005650-197508000-00006

\section{Copyrights}

Copyright for this article is retained by the author(s), with first publication rights granted to the journal.

This is an open-access article distributed under the terms and conditions of the Creative Commons Attribution license (http://creativecommons.org/licenses/by/3.0/). 